\title{
Influence of parenting efficacy, parenting stress, and acculturation stress on parent-child relations among North Korean refugee mothers
}

\author{
In-Sook Lee ${ }^{1}$, Jung-Hee Jeon ${ }^{2}$ \\ ${ }^{1}$ Associate Professor, Department of Nursing, Hannam University, Daegeon; ${ }^{2}$ Visiting Professor, College of Nursing, Ewha Womans University, Seoul, Korea
}

Purpose: This study assessed the levels of parenting efficacy, parenting stress, and acculturation stress of North Korean refugee mothers and analyzed their effects on parent-child relations. Methods: A descriptive study design was used. Data were collected during 2019, and 124 North Korean refugee mothers participated. Results: The mean score for parenting efficacy was 53.08 out of 90 , that for parent-child relations was 37.84 out of 50, and that for parenting stress was 48.57 out of 90 . The parental stress score was higher than that of child-related stress. The acculturation stress level was 90.66 out of 165 , with the highest stress levels found for social isolation and distrust and the lowest found for perceived discrimination. Parenting efficacy, parenting stress, acculturation stress, and parent-child relations were significantly related in North Korean refugee mothers. Hierarchical regression analysis showed that the final model had an explanatory power of $35 \%$ for parent-child relations $(\mathrm{F}=17.68, p<.001)$. Parenting efficacy was the variable with the largest effect on parent-child relations $(\beta=.36, p<.001)$, followed by parenting stress ( $\beta=-.24, p=.010)$. Conclusion: The findings suggest the need to identify ways to decrease parenting stress and improve parenting efficacy. Parenting education can guide North Korean refugee mothers to strengthen their parent-child interactions.

Key words: Parenting; Acculturation; Parent-child relations; Democratic People's Republic of Korea; Mothers

\author{
Corresponding author \\ In-Sook Lee \\ Department of Nursing, Hannam \\ University, 70, Hannamro, Daedoek-gu, \\ Daejon 34430, Korea \\ TEL: +82-42-629-8472 \\ FAX: +82-42-629-8472 \\ E-MAIL: is2009@hnu.ac.kr
}

Received Feb 11, 2021

Revised Mar 12, 2021

Accepted Mar 23, 2021

This is an Open Access article distributed under the terms of the Creative Commons Attribution NonCommercial License (http://creativecommons.org/licenses/by-nc/4.0/) which permits unrestricted noncommercial use, distribution, which permits unrestricted noncommercial use, distribution,
and reproduction in any medium, provided the original work is properly cited

\section{INTRODUCTION}

In recent years, crimes against humanity-including violence against and abuse of children-have become an increasingly important social issue, and proper parenting education is becoming increasingly necessary due to the behaviors and attitudes of parents who are unable to distinguish between violence and discipline and believe that children are their possessions [1]. It is important to establish a desirable parental view on social issues such as child abuse that are frequently reported by the media. There are 33,718 North Korean refugees in South Korea as of the end of September 2020; as shown by this significant number, their presence has increased to the point that they constitute an important group in South Korean society [2]. As of 2016, 44\% of North Korean refugees admitted to South Korea were families, and as of 2019, 2,531 were students enrolled in elementary, middle, and high schools [3]. With the rise in the number of North Korean refugees, problems related to their adaptation to South Korean society have also increased. North Korean refugee families experience psychological and economic burdens related to their family members left behind in North Korea, a lack of understanding and low intimacy in parent-child relations, economic difficulties and unstable jobs, stress in adapting to their life in South Korea, and traumas from their journey of defection [4]. In particular, the rise in the number of North Korean family refugees has increased the social interest in the nurturing and development of children $[1,4,5]$.

Parents are the closest personal environment that children encounter immediately after birth and significantly influence children's intellectual, emotional, social, and physical development [6]. The role of parents is also important for the holistic growth and development of children during infancy and childhood, during which children are relatively strongly influenced by their parents, and individual differences in development are observed [7].

In general, North Korean refugee mothers are likely to have experienced numerous difficulties in North Korea, and 
they learn to adapt to and nurture their children in a different culture after their defection. Furthermore, most of them have serious physical and mental injuries from their repressed lives in the closed society of North Korea and hardships during defection [5]. Sigel et al. [8] reported that a lack of self-adaptation, prior knowledge, and preparation in mothers may lead to increased psycho-emotional stress associated with parenting, which further increases the difficulties faced by mothers. The accumulation of parenting stress can also negatively affect parents. Parenting stress refers to stress from carrying out a parental role, and this ultimately has both direct and indirect effects on children's growth and development, behavioral problems, and the parent-child relationship [9]. In particular, low-income families show a relatively high level of parenting stress due to insufficient social support and their low economic level, and as economic stress increases, children are also more likely to be exposed to negative and poor parenting conditions [10]. Therefore, considering the economic level of vulnerable North Korean refugee families [1], the parenting stress levels of North Korean refugees may be high.

Moreover, the migration and settlement processes are replete with adverse experiences such as injuries, violence, and loss of family members, and settling in a new environment is a grave challenge that entails homesickness, loneliness, lack of a support system, stigma, and unemployment. These trigger acculturative stress, thereby exacerbating refugees' mental health and aggravating poverty and social isolation [11]. North Korean refugee mothers, who have endured restricted lives in a closed society in North Korea and have undergone numerous adversities during their escape process, are subject to further hardships and burdens as they migrate to South Korea, where they must adjust to a new environment and raise their children in a different culture.

Meanwhile, parenting efficacy enables effective coping with stressful situations in parenting, and it refers to parents' level of confidence and belief that they can confidently play a successful parental role based on their parenting knowledge and behavior [12]. This construct has received considerable attention from researchers investigating parent-child relations, in that it motivates parents to successfully resolve difficulties related to their children [8]. High parenting efficacy is positively correlated with positive parenting behaviors and allows individuals to face children's developmental stages with confidence. In contrast, low parenting efficacy induces conflict within the family and increases vulnerability to stress and depression [13].

The mental health and parenting efficacy of refugee parents are also correlated with the health, education, employment, and crime rates of their children [14]. Children of North Kore- an refugee families are often raised in the absence of parental care and academic support, unlike ordinary South Korean children, and they face issues such as emotional difficulties, poor academic performance, problems in adapting to the school environment, dropping out, and conflict with their parents [15].

In particular, parent-child conflict can result in a form of trauma involving the absence of one's will, caused by mothers who dismantle and reorganize the family during defection [16], and conflict can occur between North Korean refugee parents, who value patriarchal authority as in North Korean society, and their children, who quickly adapt to South Korean culture [17]. Thus, the differences in parenting methods may lead to conflict between parents and children and difficulties in forming stable parent-child relations. Previous studies have demonstrated the importance of parent-child relations for children's psychological stability and development [18]. Intimate parent-child relations and high satisfaction with parent-child relations may play a protective role in overcoming the negative aspects experienced by multi-ethnic and multi-racial families [18]. Therefore, parent-child relations may play an important role in enabling the children of North Korean refugee families to adapt to school and society and to have increased emotional stability. However, there is a lack of studies on the effects of parent-child relations, especially mother-child relations, and factors that affect these relations among North Korean refugees.

Parent education programs that suit the characteristics of North Korean refugees have not been developed owing to the limited accessibility of the subjects, and research studies by only a few groups have analyzed the parenting experiences and characteristics of North Korean refugee parents, the effects of parenting behavior on children, and the demand for child education support $[1,4,5,15]$. Furthermore, limited studies have identified the predictors of parent-child relations or conducted programs aiming to improve those relations. Therefore, this study assessed the levels of parenting efficacy, parenting stress, and acculturation stress of North Korean refugee mothers and analyzed their effects on parent-child relations in order to present basic data for the development of support programs that consider the unique characteristics of refugee families.

\section{METHODS}

Ethics statement: This study was approved by the Institutional Review Board of Hannam University (No. 2019-02-110918). Informed consent was obtained from the participants. 


\section{Study Design}

This was a descriptive research study conducted to evaluate parenting efficacy, parenting stress, and acculturation stress of North Korean refugee mothers and analyze the effects of these factors on parent-child relations.

\section{Subjects}

The subjects of this study were North Korean refugees with children under the age of 20 years who were registered from January 2019 to December 2019 at Saejowi, a nonprofit organization in South Korea that assists North Korean refugee resettlement by providing medical assistance, counseling, training, and employment services, and local North Korean refugee counseling centers. The number of subjects was calculated using $G^{*}$ Power 3.1.7, and the required number of subjects for regression analysis with an effect size of .15 , a power of .80 , a significance level of .05 , and six predictive factors was 98 . Considering a dropout rate of roughly $20 \%, 118$ subjects were required. In this study, 138 mothers who were able to communicate, understood the purpose and methods of this study, and agreed to participate in the study were included, and data from 124 mothers were secured, excluding eight subjects whose responses were below the expected quality.

\section{Study Tools}

\section{1) Parenting efficacy}

Parenting efficacy, also referred to as parental efficacy, was assessed using the Parenting Sense of Competence scale for parents with children under 18 years of age, which was originally developed by Gibaud-Wallston and Wandersman [19] and adapted and revised by Shin and Chung [12]. The tool consists of 16 items on parenting efficacy and anxiety; the items are rated on a 5-point Likert scale ranging from 1 (strongly disagree) to 5 (strongly agree). Items with negative statements are modified to positive statements and reversescored, and a higher score indicates higher perceived parenting efficacy. In the study by Shin and Chung [12] and our study, the Cronbach's $\alpha$ values for all items were .78 and .77, respectively.

\section{2) Parenting stress}

The Parenting Stress Index was utilized by modifying the tool developed by Kim [20]. The contents of the tool were modified using language that North Korean refugees could understand by consulting two nursing professors, one psychiatrist, and a nurse at Hanawon, which is a South Korean settlement support center for the re-education of North Kore- an refugees. The tool measures the overall stress that can occur between parents and children and consists of 18 items, including 8 and 10 items on parents and children, respectively. The items are rated on a 5-point Likert scale ranging from 1 (strongly disagree) to 5 (strongly agree). Items with negative statements are modified to positive statements and reversescored, and a higher score indicates higher parenting stress. At the time of development, the Cronbach's $\alpha$ values were $.89, .85$, and .88 , for the entire tool, the items on parents, and the items on children, respectively [20]. In our study, these values were $.75, .60$, and .74 , respectively.

\section{3) Acculturation stress}

The Acculturative Stress Scale for international students, which was developed by Sandhu and Asrabadi [21] and revised and supplemented by Lee [22] for a total of 33 questions, was reorganized into language that considered the characteristics of the target subjects. North Korea-related teachers in Hanawon and North Korean refugees were consulted for further modification. The tool consists of seven sub-domains with six, four, five, three, four, two, and nine items on perceived discrimination, nostalgia, perceived hostility, culture shock, fear, guilt, and other problems related to social isolation, inferiority, distrust, and communication, respectively. The items are rated on a 5-point Likert scale from 1 (strongly disagree) to 5 (strongly agree). Items with negative statements that could cause confusion in the subjects were modified to positive statements and reverse-scored. A higher score indicated higher acculturation stress. Cronbach's $\alpha$ at the time of scale development was .94 [21]. In this study, it was .85.

\section{4) Parent-child relations}

Parent-child relations were assessed using the tool developed by Kim [23]. The tool consists of 10 items in total. The items are rated on a 5-point Likert scale ranging from 1 (strongly disagree) to 5 (strongly agree), and a higher score corresponds to more positive parent-child relations. At the time of development, Cronbach's $\alpha$ was .87 [23], and in our study, it was .88 .

\section{Data Collection Method and Procedure}

After obtaining approval from the Institutional Review Board of Hannam University (No. 2019-02-11-0918), permission was obtained from the representative of Saejowi to recruit North Korean refugee mothers with children through the cooperation of local counselors. The survey was conducted by a research assistant who explained the purpose and content of this study in a way that was easy for the subjects to understand. Additionally, the subjects were explained that 
this was an anonymous survey with no possible leakage of personal information or threat to personal safety and that participation was voluntary without any negative effects. The subjects were also informed that they could withdraw from the study at any time before, during, or after the study without any disadvantages. We explained that all information would be coded and safely processed only for the purpose of this study, and those who voluntarily agreed to participate in the study were selected. A self-report questionnaire was then completed by the subjects after they provided written consent for participation. Approximately 15-20 minutes were required to complete the questionnaire, and a small gift was given after questionnaire completion as a token of gratitude for participation.

\section{Data Analysis}

The collected data were analyzed using SPSS version 21.0 (IBM Corp., Armonk, NY, USA). The general characteristics of the subjects were presented as real numbers and percentages, and general characteristics, parenting efficacy, parenting stress, acculturation stress, and parent-child relations were presented as percentage, mean, and standard deviation (SD). Differences in parenting efficacy, parenting stress, acculturation stress, and parent-child relations according to general characteristics were analyzed using the t-test and analysis of variance (ANOVA). The correlations between the variables were analyzed using Pearson correlation coefficients, and factors that affected parent-child relations were analyzed using hierarchical multiple regression.

\section{RESULTS}

\section{General Characteristics of Subjects and Differences in Variables According to General Characteristics}

More than $70 \%$ of the subjects were in their 30s and 40s. Of these, $64.6 \%$ had defected alone to South Korea, and $19.4 \%$ and $45.2 \%$ were married in North Korea or China and in a third country, respectively. Three-quarters $(75.0 \%)$ of the subjects had a middle and high school education. Regarding the number of children, $54.0 \%, 39.5 \%$, and $6.5 \%$ of the subjects had one, two, and three children, respectively. Prior to their defection, $38.8 \%$ of the subjects were laborers. Slightly more than half $(54.0 \%)$ of the subjects had been living in South Korea for 4-6 months. Parenting efficacy, parenting stress, acculturation stress, and parent-child relations were not significantly different according to the general characteristics of the subjects (Table 1).

\section{Parenting Efficacy, Parenting Stress, and Parent-Child Relations}

The mean score for parenting efficacy of the subjects was $53.08 \pm 6.83$ out of 90 points ( $3.32 \pm 0.43$ on a 5 -point scale), and the score for parenting stress was $48.57 \pm 7.39$ out of 90 points ( $2.70 \pm 0.41$ points on a 5 -point scale). In detail, the scores of items on parental stress and child-related stress were $23.73 \pm$ 4.05 points ( $2.97 \pm 0.51$ points on a 5 -point scale) and $24.85 \pm$ 4.77 points ( $2.49 \pm 0.48$ points on a 5 -point scale), respectively, suggesting that parental stress was higher than child-related stress. Parent-child relations showed a mean score of $37.84 \pm$ 85.90 out of 50 points ( $3.78 \pm 0.59$ on a 5 -point scale) (Table 2 ).

\section{Acculturation Stress}

A mean score of $2.75 \pm 0.42$ out of 5 points was observed for acculturation stress. For its sub-domains, other problems related to social isolation, inferiority, distrust, and communication had the highest score with $2.98 \pm 0.47$ points, followed by guilt with $2.88 \pm 0.83$ points, which was higher than the total mean score. The sub-domain with the lowest score was perceived discrimination, with $2.32 \pm 0.59$ points (Table 2 ).

\section{Correlations between Parenting Efficacy, Parenting Stress, Acculturation Stress, and Parent-Child Relations}

Parenting efficacy was negatively correlated with parenting stress $(\mathrm{r}=-.54, p<.001)$ and acculturation stress $(\mathrm{r}=-.43, p<$ $.001)$ and positively correlated with parent-child relations $(\mathrm{r}=$ $.53, p<.001)$. In other words, higher parenting efficacy was associated with more positive parent-child relations, while lower parenting efficacy was associated with higher stress. Parentchild relations showed a negative correlation with parenting stress $(\mathrm{r}=-.49, p<.001)$ and acculturation stress $(\mathrm{r}=-.39, p<.001)$, meaning that more positive parent-child relations were associated with lower parenting stress and acculturation stress. Additionally, parenting stress was positively correlated with acculturation stress $(\mathrm{r}=.48, p<.001)$, indicating that higher levels of acculturation stress were associated with higher parenting stress (Table 3).

\section{Factors Affecting Parent-Child Relations}

Hierarchical regression analysis was performed by inputting acculturation stress, parenting stress, and parenting efficacy at each stage to identify factors that affected parent-child relations. Moreover, the education level of the subjects, which was observed as a meaningful variable in previous studies $[1,24]$ and needs to be considered for the development of edu- 
Table 1. General Characteristics and the Degree of Parenting Efficacy, Parenting Stress, Acculturation Stress, and Parent-Child Relations $(N=124)$

\begin{tabular}{|c|c|c|c|c|c|c|c|c|c|c|}
\hline \multirow[t]{2}{*}{ Variables } & \multirow[t]{2}{*}{ Categories } & \multirow{2}{*}{$\begin{array}{l}\mathrm{n}(\%) \text { or } \\
\mathrm{M} \pm \mathrm{SD}\end{array}$} & \multicolumn{2}{|c|}{ Parenting efficacy } & \multicolumn{2}{|c|}{ Parenting stress } & \multicolumn{2}{|c|}{ Acculturation stress } & \multicolumn{2}{|c|}{$\begin{array}{l}\text { Parent-child } \\
\text { relations }\end{array}$} \\
\hline & & & $\mathrm{M} \pm \mathrm{SD}$ & $\mathrm{F}(p)$ & $\mathrm{M} \pm \mathrm{SD}$ & $\mathrm{F}(p)$ & $\mathrm{M} \pm \mathrm{SD}$ & $\mathrm{F}(p)$ & $\mathrm{M} \pm \mathrm{SD}$ & $\mathrm{F}(p)$ \\
\hline Age (year) & $\begin{array}{l}\leq 29 \\
30-39 \\
40-49 \\
\geq 50\end{array}$ & $\begin{array}{r}14(11.3) \\
56(45.2) \\
31(25.0) \\
23(18.5) \\
36.7 \pm 9.1\end{array}$ & $\begin{array}{l}54.43 \pm 5.15 \\
53.05 \pm 7.81 \\
52.84 \pm 5.83 \\
52.65 \pm 6.68\end{array}$ & $\begin{array}{l}0.22 \\
(.882)\end{array}$ & $\begin{array}{l}48.64 \pm 6.27 \\
48.21 \pm 8.19 \\
48.19 \pm 7.33 \\
49.91 \pm 6.22\end{array}$ & $\begin{array}{l}0.32 \\
(.812)\end{array}$ & $\begin{array}{l}90.00 \pm 130.21 \\
87.68 \pm 12.60 \\
92.68 \pm 15.23 \\
95.61 \pm 14.10\end{array}$ & $\begin{array}{l}2.14 \\
(.099)\end{array}$ & $\begin{array}{l}39.36 \pm 4.50 \\
38.21 \pm 6.74 \\
37.13 \pm 5.37 \\
36.96 \pm 5.10\end{array}$ & $\begin{array}{l}0.70 \\
(.553)\end{array}$ \\
\hline Spou & $\begin{array}{l}\text { With spouse from North Korea } \\
\text { Defection alone without spouse } \\
\text { Defection alone without spouse, } \\
\text { married in a third country } \\
\text { Cohabitation }\end{array}$ & $\begin{array}{c}5(4.0) \\
24(19.4) \\
56(45.2) \\
39(31.4)\end{array}$ & $\begin{array}{l}57.20 \pm 9.42 \\
53.13 \pm 6.05 \\
53.27 \pm 5.93 \\
52.27 \pm 8.10\end{array}$ & $\begin{array}{l}0.81 \\
(.492)\end{array}$ & $\begin{array}{l}48.40 \pm 4.72 \\
49.67 \pm 5.70 \\
48.23 \pm 9.07 \\
48.41 \pm 5.89\end{array}$ & $\begin{array}{l}0.22 \\
(.884)\end{array}$ & $\begin{array}{l}90.20 \pm 10.52 \\
90.42 \pm 14.19 \\
90.55 \pm 15.61 \\
91.03 \pm 11.51\end{array}$ & $\begin{array}{c}0.01 \\
(.998)\end{array}$ & $\begin{array}{l}36.00 \pm 5.79 \\
37.42 \pm 4.60 \\
38.39 \pm 5.37 \\
37.54 \pm 6.97\end{array}$ & $\begin{array}{l}0.40 \\
(.756)\end{array}$ \\
\hline $\begin{array}{r}\text { Educ } \\
\text { lev }\end{array}$ & $\begin{array}{l}\text { Middle-high s } \\
\geq \text { College gra }\end{array}$ & $\begin{array}{l}10(8.1) \\
93(75.0) \\
21(16.9)\end{array}$ & $\begin{array}{l}50.30 \pm 5.87 \\
53.05 \pm 6.80 \\
54.52 \pm 7.25\end{array}$ & $\begin{array}{l}1.31 \\
(.275)\end{array}$ & $\begin{array}{l}52.80 \pm 7.47 \\
47.82 \pm 7.42 \\
49.90 \pm 6.62\end{array}$ & $\begin{array}{l}2.52 \\
(.084)\end{array}$ & $\begin{array}{l}96.60 \pm 16.35 \\
90.29 \pm 13.74 \\
89.48 \pm 12.94\end{array}$ & $\begin{array}{l}1.03 \\
(.359)\end{array}$ & $\begin{array}{l}38.20 \pm 5.88 \\
38.04 \pm 5.85 \\
36.76 \pm 6.28\end{array}$ & $\begin{array}{l}0.42 \\
(.657)\end{array}$ \\
\hline $\begin{array}{r}\text { Num } \\
\text { chil }\end{array}$ & $\begin{array}{l}1 \\
2 \\
\geq\end{array}$ & $\begin{array}{c}67(54.0) \\
49(39.5) \\
8(6.5)\end{array}$ & $\begin{array}{l}52.94 \pm 7.05 \\
53.49 \pm 6.69 \\
51.75 \pm 6.30\end{array}$ & $\begin{array}{l}0.25 \\
(.778)\end{array}$ & $\begin{array}{l}48.90 \pm 7.23 \\
48.00 \pm 7.80 \\
48.38 \pm 6.67\end{array}$ & $\begin{array}{l}0.26 \\
(.775)\end{array}$ & $\begin{array}{l}89.63 \pm 13.67 \\
90.78 \pm 14.22 \\
98.63 \pm 11.39\end{array}$ & $\begin{array}{c}1.53 \\
(.221)\end{array}$ & $\begin{array}{l}37.91 \pm 5.98 \\
37.94 \pm 5.79 \\
36.63 \pm 6.48\end{array}$ & $\begin{array}{l}0.18 \\
(.836)\end{array}$ \\
\hline $\begin{array}{l}\text { Occupation } \\
\text { before } \\
\text { defection* }\end{array}$ & $\begin{array}{l}\text { Unemployed } \\
\text { Farmer } \\
\text { Laborer } \\
\text { Professional or soldier or student } \\
\text { Self-employment or other }\end{array}$ & $\begin{array}{l}23(18.5) \\
16(12.9) \\
48(38.8) \\
14(11.3) \\
23(18.5)\end{array}$ & $\begin{array}{l}54.30 \pm 6.47 \\
51.88 \pm 6.27 \\
51.60 \pm 7.32 \\
55.86 \pm 5.93 \\
54.09 \pm 6.57\end{array}$ & $\begin{array}{l}1.61 \\
(.177)\end{array}$ & $\begin{array}{l}48.57 \pm 5.03 \\
48.50 \pm 6.39 \\
49.29 \pm 7.95 \\
43.36 \pm 11.10 \\
50.30 \pm 4.76\end{array}$ & $\begin{array}{l}2.26 \\
(.275)\end{array}$ & $\begin{array}{l}90.52 \pm 11.93 \\
94.25 \pm 11.44 \\
92.52 \pm 15.35 \\
82.71 \pm 15.39 \\
89.26 \pm 11.62\end{array}$ & $\begin{array}{l}1.74 \\
(.145)\end{array}$ & $\begin{array}{l}37.57 \pm 6.58 \\
37.25 \pm 5.94 \\
37.08 \pm 6.08 \\
41.57 \pm 5.64 \\
37.83 \pm 4.34\end{array}$ & $\begin{array}{l}1.69 \\
(.157)\end{array}$ \\
\hline $\begin{array}{l}\text { Occupation } \\
\text { before } \\
\text { defection }^{\dagger}\end{array}$ & $\begin{array}{l}\text { Unemployed } \\
\text { Farmer } \\
\text { Professional or soldier or student } \\
\text { Self-employment or other }\end{array}$ & $\begin{array}{l}27(21.8) \\
35(28.2) \\
18(14.5) \\
44(35.5)\end{array}$ & $\begin{array}{l}50.96 \pm 6.22 \\
53.17 \pm 6.92 \\
53.22 \pm 6.55 \\
54.25 \pm 7.13\end{array}$ & $\begin{array}{l}1.31 \\
(.274)\end{array}$ & $\begin{array}{l}49.67 \pm 9.21 \\
47.97 \pm 6.64 \\
49.00 \pm 5.56 \\
48.57 \pm 7.53\end{array}$ & $\begin{array}{l}0.33 \\
(.807)\end{array}$ & $\begin{array}{l}93.22 \pm 15.09 \\
91.91 \pm 14.44 \\
89.83 \pm 14.13 \\
88.43 \pm 12.45\end{array}$ & $\begin{array}{l}0.80 \\
(.494)\end{array}$ & $\begin{array}{l}37.52 \pm 5.99 \\
38.97 \pm 5.22 \\
36.72 \pm 5.68 \\
37.59 \pm 6.46\end{array}$ & $\begin{array}{l}0.69 \\
(.558)\end{array}$ \\
\hline $\begin{array}{l}\text { Period } \\
\text { post-arrival in } \\
\text { South Korea } \\
\text { (month) }\end{array}$ & $\begin{array}{l}\leq 3 \\
4-6 \\
7-12 \\
\geq 13\end{array}$ & $\begin{array}{c}31(25.0) \\
67(54.1) \\
20(16.1) \\
6(4.8)\end{array}$ & $\begin{array}{l}53.26 \pm 7.14 \\
53.40 \pm 5.85 \\
53.30 \pm 8.75 \\
47.83 \pm 7.88\end{array}$ & $\begin{array}{l}1.25 \\
(.294)\end{array}$ & $\begin{array}{l}48.00 \pm 6.13 \\
48.73 \pm 7.72 \\
46.90 \pm 7.16 \\
55.33 \pm 8.24\end{array}$ & $\begin{array}{l}2.15 \\
(.098)\end{array}$ & $\begin{array}{l}90.84 \pm 12.37 \\
90.66 \pm 14.59 \\
90.75 \pm 12.04 \\
89.50 \pm 20.58\end{array}$ & $\begin{array}{l}0.02 \\
(.997)\end{array}$ & $\begin{array}{l}38.42 \pm 4.75 \\
37.99 \pm 5.85 \\
36.70 \pm 6.95 \\
37.00 \pm 8.72\end{array}$ & $\begin{array}{l}0.40 \\
(.755)\end{array}$ \\
\hline
\end{tabular}

${ }^{*}$ North Korea; ${ }^{\dagger}$ China or third country.

Table 2. Parenting Efficacy, Parenting Stress, Parent-Child Relations, and Acculturation Stress $(N=124)$

\begin{tabular}{|c|c|c|c|c|}
\hline Variables & Categories & $\mathrm{M} \pm \mathrm{SD}$ & Range & $\begin{array}{c}\mathrm{M} \pm \mathrm{SD} \\
\text { (5 points) }\end{array}$ \\
\hline Parenting efficacy & & $53.08 \pm 6.83$ & $38-73$ & $3.32 \pm 0.43$ \\
\hline Total parenting stress & $\begin{array}{l}\text { Parental stress } \\
\text { Child-related stress }\end{array}$ & $\begin{array}{l}48.57 \pm 7.39 \\
23.73 \pm 4.05 \\
24.85 \pm 4.77\end{array}$ & $\begin{array}{r}19-65 \\
8-32 \\
11-38\end{array}$ & $\begin{array}{l}2.70 \pm 0.41 \\
2.97 \pm 0.51 \\
2.49 \pm 0.48\end{array}$ \\
\hline Parent-child relations & & $37.84 \pm 5.90$ & $21-50$ & $3.78 \pm 0.59$ \\
\hline Acculturation stress & $\begin{array}{l}\text { Perceived discrimination } \\
\text { Homesickness } \\
\text { Perceived hostility } \\
\text { Culture shock } \\
\text { Fear } \\
\text { Guilt } \\
\text { Others* } \\
\text { Total score }\end{array}$ & $\begin{array}{r}13.94 \pm 3.55 \\
14.39 \pm 2.90 \\
11.98 \pm 2.85 \\
7.35 \pm 1.88 \\
10.43 \pm 2.82 \\
5.77 \pm 1.65 \\
26.81 \pm 4.26 \\
90.66 \pm 13.83\end{array}$ & $\begin{array}{c}6-23 \\
5-20 \\
5-18 \\
3-11 \\
5-17 \\
2-10 \\
13-37 \\
56-130\end{array}$ & $\begin{array}{l}2.32 \pm 0.59 \\
2.60 \pm 0.72 \\
2.40 \pm 0.57 \\
2.45 \pm 0.63 \\
2.61 \pm 0.71 \\
2.88 \pm 0.83 \\
2.98 \pm 0.47 \\
2.75 \pm 0.42\end{array}$ \\
\hline
\end{tabular}

*Social isolation, inferiority, distrust, sorrow, etc. 
cation programs for North Korean refugees, was input in the first stage as well, although it did not have a significant effect on parent-child relations. The results of the analysis are shown in Table 4.

Autocorrelation (Durbin-Watson statistic=1.99), normality, and linearity (normal P-P plot and histogram of residuals), and equal variance (scatter plot) of residuals were assessed to review the basic assumptions of regression analysis. The tolerance limit to confirm the multicollinearity of the errors in this model was .63-.99, which was less than 1.0, and the variance inflation factor was 1.01-1.59, which did not exceed the standard value of 10 . Therefore, the basic assumptions of regression analysis were satisfied.

The first model, in which the education level and acculturation stress of the subjects were included, showed an explanatory power of $15 \%$ for parent-child relations, and the model was statistically significant $(\mathrm{F}=11.98, p<.001)$. In the first model with general characteristics, acculturation stress had a significant effect on parent-child relations $(\beta=-.40, p<$ .001). The second model, which included parenting stress, had an explanatory power of $27 \%$ for parent-child relations $(\Delta$ $\left.\mathrm{R}^{2}=.12, \mathrm{~F}=15.99, p<.001\right)$; in this model, parenting stress $(\beta=$ $-.40, p<.001)$ and acculturation stress $(\beta=-.21, p=.019)$ had effects on parent-child relations. Lastly, the third model, which included parenting efficacy, had an explanatory power of $35 \%$ for parent-child relations, which was statistically significant $\left(\Delta \mathrm{R}^{2}=.09, \mathrm{~F}=17.68, p<.001\right)$. In the final model, the variable with the largest effect on parent-child relations was parenting efficacy $(\beta=.36, p<.001)$, followed by parenting stress $(\beta=-.24$, $p=.010)$.

\section{DISCUSSION}

This study assessed the levels of parenting efficacy, parenting stress, and acculturation stress from various adaption processes in North Korean refugee mothers, and the effects of these factors on parent-child relations were also evaluated to provide basic data for parenting education that can promote the development and stable settlement of refugee families.

The parenting efficacy of the subjects was 53.08 out of 90 points, which corresponded to 3.32 points on a 5-point scale. The score was lower than the score of 3.60 points in mothers of multi-cultural families with adolescent children [25], which were assessed using the same tool. Parenting efficacy refers to the parent's ability to raise children and level of confidence in the parental role [12], and it positively affects the growth and development of children and is essential for the psychological stability of children [13]. Various experiences in the process of defection can negatively affect the social adaptation of North Korean refugee mothers through value confusion, post-traumatic stress, and psychological pain, which can hinder mothers' parenting. In particular, North Korean refugees have uncertain beliefs about their roles as parents [4], and our findings confirm the need to improve the parenting efficacy of North Korean refugee mothers, who are likely to lack confidence in parenting. Parenting efficacy has been confirmed to be a de-

Table 3. Correlations between Research Variables $(N=124)$

\begin{tabular}{lcccc}
\hline Variables & Parenting efficacy & Parent-child relations & & Parenting stress \\
\cline { 2 - 3 } Parent-child relations & $\mathrm{r}(p)$ & $\mathrm{r}(p)$ & $\mathrm{r}(p)$ \\
Parenting stress & $-.53(<.001)$ & $-.49(<.001)$ & $-.001)$ & $.03(<.001)$ \\
Acculturation stress & $-.43(<.001)$ & & $.001)$ \\
\hline
\end{tabular}

Table 4. Hierarchical Regression Analysis of Variables Influencing Parent-Child Relations $(N=124)$

\begin{tabular}{|c|c|c|c|c|c|c|c|c|c|c|c|c|c|c|c|}
\hline \multirow{2}{*}{ Variables } & \multicolumn{5}{|c|}{ Step 1} & \multicolumn{5}{|c|}{ Step 2} & \multicolumn{5}{|c|}{ Step 3} \\
\hline & B & SE & $\beta$ & $\mathrm{t}$ & $p$ & B & SE & $\beta$ & $\mathrm{t}$ & $p$ & B & SE & $\beta$ & $\mathrm{t}$ & $p$ \\
\hline Educational level & -1.36 & .99 & -.11 & 1.36 & .176 & -1.28 & .93 & -.11 & 1.38 & .171 & -1.73 & .88 & -.15 & 1.97 & .051 \\
\hline Acculturation stress & -0.17 & .03 & -.40 & 4.82 & $<.001$ & -0.09 & .04 & -.21 & 2.38 & .019 & -0.06 & .04 & -.14 & 1.58 & .116 \\
\hline Parenting stress & & & & & & -0.32 & .07 & -.40 & 4.49 & $<.001$ & -0.19 & .07 & -.24 & 2.61 & .010 \\
\hline Parenting efficacy & & & & & & & & & & & 0.31 & .08 & .36 & 4.07 & $<.001$ \\
\hline $\mathrm{R}^{2}\left(\Delta \mathrm{R}^{2}\right) / \operatorname{Adj} . \mathrm{R}^{2}$ & \multicolumn{5}{|c|}{$.17 / .15$} & \multicolumn{5}{|c|}{$.29(.12) / .27$} & \multicolumn{5}{|c|}{$.37(.09) / .35$} \\
\hline $\mathrm{F}(p)$ & \multicolumn{5}{|c|}{$11.98(<.001)$} & \multicolumn{5}{|c|}{$15.99(<.001)$} & \multicolumn{5}{|c|}{$17.68(<.001)$} \\
\hline
\end{tabular}


terminant of the quality of parenting [26] and a mediator that leads to desirable parenting behaviors in the relationship between factors that influence parenting behaviors. Thus, it is important to devise strategies that enhance parenting efficacy among North Korean refugee parents to promote healthy parenting.

In our study, the total score for parenting stress was 48.57 out of 90 points, which was 2.70 points on a 5-point scale. The sub-domains of parental stress and child-related stress showed scores of 2.97 and 2.49, respectively, suggesting that parental stress was higher than child-related. Although the same tool was not used for evaluation, our finding is similar to the level of parenting stress in married migrant women, which was reported to be 2.73 points [27]. Humans allocate psychological resources to endure their own emotional difficulties when there is high psychological stress, and this makes it difficult to react sensitively to the emotions and desires of children [28]. It is thought that the psychological burden of North Korean refugee mothers is high, as they have to carefully examine the emotional states of their children and themselves in complicated and unpredictable situations, including their traumatic experiences during defection. Parenting stress can cause side effects on efforts to adapt to the responsibilities and roles of parents [10], and negative emotions from parents can directly affect or be a mediating factor for children's development [14]. Active interventions by clinical experts are urgently required to help relieve parenting stress, and education support is needed to clearly explore stress-inducing factors and ensure the healthy development of children and high-quality parenting.

Parent-child relations play an important role in the development of children. In this study, a score of 3.78 points on a 5-point scale was observed for parent-child relations, and although different tools were used for assessment, the score in our study was lower than the 4.29 points for parent-child relations perceived by married migrant women [29]. In a study that evaluated parent-child relations, North Korean refugees had difficulties in raising and educating their children; however, the types of difficulties were expressed in different ways. In that study, the participants expressed difficulties in preparing meals for and looking after the health of their children, which reflected food shortages in North Korea at the time [13]. In contrast, participants in South Korean studies discussed the burden of private education expenses and difficulties in school study and career guidance for children [13]. Children of North Korean refugees are vulnerable to social, psychological, and cultural developmental problems like their parents. Improper formation of parent-child attachment, emotional relations, and psychological bonds in the process of settling into a new society would lead to an increased risk of neg- ative consequences for the growth and development of children [29].

In our study, a mean score of 2.75 on a 5-point scale was observed for acculturation stress. For its sub-domains, other problems related to social isolation, inferiority, distrust, and communication had the highest score at 2.98 points, followed by guilt with 2.88 points, and the sub-domain with the lowest score was perceived discrimination with 2.32 points. However, our score is less than the score of 3.35 points observed in a study by Lee et al. [5]. In that study, perceived hostility was had the highest score (3.81 points), followed by perceived discrimination, culture shock, and fear, with scores of 3.78, 3.65, and 3.63 points, respectively. The sub-domain with the lowest score was nostalgia with 2.84 points, which is different from the below-average score for that sub-domain observed in our study. Compared to the past, the overall level of acculturation stress has decreased, and perceptions of hostility and discrimination have also been significantly reduced. However, problems related to social isolation, inferiority, distrust, and communication were still high, and stress caused by guilt toward the family members left in North Korea was high. Thus, refugees may experience conflict within the family in South Korea, and this may lead to separation of families, which suggests the importance of psychological balance between refugee family members in South Korea and those left behind in North Korea.

Similar to the results of a previous study [25], lower parenting efficacy was associated with higher parenting and adaption stress in this study. Additionally, parenting stress was positively correlated with adaption stress, suggesting that higher acculturation stress was associated with higher parenting stress. Parent-child relations were negatively correlated with parenting and adaption stress, indicating more positive parent-child relations were associated with lower parenting and adaption stress. In other words, parenting efficacy is a determinant of parenting behaviors [11] that enables parents to overcome parenting-related stress or difficulties encountered in the environment and reduces conflicts with children, ultimately improving parent-child relations. Therefore, hierarchical regression analysis was performed to confirm the relative effects of the variables on the parent-child relations in North Korean refugee mothers, and each model was statistically significant $(p<.001)$. Model 1 , a hierarchical regression analysis comprising participants' education level and acculturative stress, explained $15 \%$ of the variance in parent-child relations. Model 2, which additionally included parenting stress, a negative parenting factor, explained $27 \%$ of the variance in parent-child relations. Finally, model 3, which additionally included parenting efficacy, a positive parenting factor, explained $35 \%$ of variance in the parent-child relations, and in 
the final model, parenting efficacy and parenting stress were potential predictors of parent-child relations. Establishing correct values and beliefs and overcoming parenting stress with a confident attitude would help foster a positive relationship with children. Children's physical and mental health and family characteristics, behaviors, and interactions are interrelated with each other, and the quality of parent-child relations is an essential factor for the healthy life of children $[7,8,14]$. Therefore, it is important to strengthen social support systems that help North Korean refugee mothers effectively manage parenting stress and enhance their parenting efficacy. Mothers' parenting knowledge can reduce parenting stress $[8,12]$ and parenting education programs [11] such as group art therapies [30] also reduce parental stress. Thus, expanding opportunities for parenting education to reduce parenting stress can also improve parenting behaviors. Further, these parenting education programs should be individualized, taking into account the participants' demographic factors such as family structure, family function, economic status, sociocultural background, and parents' education level [20], as well as parenting needs.

In particular, effective communication measures such as listening and sympathizing for positive interactions with receptive attitudes toward children and educational support to strengthen parenting interaction skills would be necessary to form strong parent-child relations. For those who require help from clinical experts, strategies to improve interactions through individual counseling need to be sought, and family counseling programs for the whole family (i.e., not limited to mothers), activities for parents and children, and therapeutic play activities [30] would be necessary for North Korean refugee mothers to develop effective parenting skills that can promote positive development of their children and induce highquality interactions to promote affection and trust between family members.

This study provides information on the parenting of North Korean refugee mothers by showing the influence of parenting efficacy and parenting stress on the relations between North Korean refugee mothers and children. As parenting efficacy, self-esteem, and social acculturation stress of North Korean refugee fathers were not assessed, the influence of these factors through other parameters could not be evaluated. However, this study is significant in that it is the first to present the influence of parenting efficacy and parenting stress on the relations between North Korean refugee mothers and children. Nonetheless, the results have limited generalizability, as only the minimal number of subjects required for data analysis was included in the study owing to the limited accessibility of the target subjects. Thus, it would be necessary to include a higher number of subjects in future studies. In ad- dition, although we did not include factors such as children's age and sex in our analysis, future studies should also examine parenting behaviors and specific parenting difficulties according to children's traits, including their personalities or behavioral and emotional characteristics, when assessing parenting educational needs. Since many variables affect childrearing among migrant refugees, it is also necessary to compare them with South Korean mothers through qualitative research on their parenting stress and parenting efficacy factors. It would also be necessary to develop and verify the effects of customized parenting education programs tailored to the characteristics of North Korean refugee families.

\section{CONCLUSION}

Parenting is one of the difficulties faced by North Korean refugee families, who experience physical and psychological stress during defection and adaptation in South Korean society. In this study, parenting efficacy, parenting stress, acculturation stress, and parent-child relations of North Korean refugee mothers were significantly related, and parenting efficacy and parenting stress influenced parent-child relations. Thus, parenting education interventions that improve parenting efficacy and alleviate parenting stress should be developed to foster positive parenting behaviors and desirable parent-child relations, in order to promote healthy parent-child interactions. Healthy parenting in North Korean refugee families will promote positive development of the children and help families to have a healthy and quality life in South Korean society. We believe that the findings of this study will be valuable as baseline data for developing programs that can help North Korean refugees and migrant families to settle stably and raise their children in a new environment.

\section{ORCID}

In-Sook Lee https://orcid.org/0000-0003-4156-9685

Jung-Hee Jeon https://orcid.org/0000-0002-8045-7064

\section{Authors' contribution}

Conceptualization: all authors; Data collection: Jung-Hee Jeon; Formal analysis: In-Sook Lee; Writing-original draft: Jung-Hee Jeon; Writing-review and editing: In-Sook Lee; Final approval of published version: all authors.

\section{Conflict of interest}

No existing or potential conflict of interest relevant to this article was reported. 


\section{Funding}

This study was supported by a National Research Foundation of Korea (NRF) grant funded by the Korean government (No. NRF-2019R1C1C1003087).

\section{Data availability}

Please contact the corresponding author for data availability.

\section{Acknowledgements}

None.

\section{REFERENCES}

1. Lee IS, Jeon JH. Effects of parenting stress in North Korean refugee fathers on their parenting behavior. Child Health Nursing Research. 2016;22(3):182-189.

https://doi.org/10.4094/chnr.2016.22.3.182

2. Ministry of Unification. The number of North Korea refugees entering South Korea, as of the end of September, 2020 [Internet]. Seoul: Ministry of Unification; 2020 [cited 2021 January 20]. Available from: https://www.unikorea.go.kr/unikorea/business/NKDefectors Policy/status/lately/

3. Korea Educational Development Institute. Education status for North Korean defectors [Internet]. Jincheon: Korea Educational Development Institute; 2019 [cited 2021 January 20]. Available from: https://www.hub4u.or.kr/hub/edu/status01.do

4. Park SK, Ahn SH. A study on the variables affecting parenting efficacy of North Korean refugee mothers: With a focus on marital satisfaction, social support, and acculturation. Korean Journal of Child Studies. 2014;35(4):103-122.

https://doi.org/10.5723/KJCS.2014.35.4.103

5. Lee IS, Park HR, Park HJ, Park YH. Relationships between parenting behavior, parenting efficacy, adaptation stress and post traumatic stress disorder among mothers who defected from North Korean. Child Health Nursing Research. 2010;16(4):360-368.

https://doi.org/10.4094/jkachn.2010.16.4.360

6. Maggi S, Irwin LJ, Siddiqi A, Hertzman C. The social determinants of early child development: An overview. Journal of Pediatrics and Child Health. 2010;46(11):627-635. https://doi.org/10.1111/j.1440-1754.2010.01817.x

7. Thomas L, Lloyd J, Riley A, Caffrey P, Wallbank A, Harris M. Designing a culturally appropriate intervention for new migrant mothers. Australian Journal of Primary Health. 2019;25(3):51-52. https://doi.org/10.1071/PYv25n3abs

8. Sigel IE, McGillicuddy-DeLisi AV, Goodnow JJ. Parental belief systems: The psychological consequences for children. 2nd ed. London: Lawrence Erlbaum Associates, Inc.; 1992. p. 319-346.
9. Huizink AC, Menting B, De Moor MHM. From prenatal anxiety to parenting stress: A longitudinal study. Archives of Women's Mental Health. 2017;20(5):663-672.

https://doi.org/10.1007/s00737-017-0746-5

10. Ward KP, Lee SJ. Mothers' and fathers' parenting stress, responsiveness, and child wellbeing among low-income families. Children and Youth Services Review. 2020;116:105218.

https://doi.org/10.1016/j.childyouth.2020.105218

11. Osman F, Klingberg-Allvin M, Flacking R, Schön UK. Parenthood in transition - Somali-born parents' experiences of and needs for parenting support programmes. BMC International Health and Human Rights. 2016;16:7. https://doi.org/10.1186/s12914-016-0082-2

12. Shin SJ, Chung MJ. Effects of stress, social support and efficacy on mothers' parenting behaviors. Korean Journal of Child Studies. 1998;19(1):27-42.

13. Sanders MR, Woolley ML. The relationship between maternal selfefficacy and parenting practices: Implications for parent training. Child Care, Health and Development. 2005;31(1):65-73. https://doi.org/10.1111/j.1365-2214.2005.00487.x

14. Johnson JG, Smailes E, Cohen P, Kasen S, Brook JS. Anti-social parental behaviour, problematic parenting and aggressive offspring behaviour during adulthood: A 25-year longitudinal investigation. The British Journal of Criminology. 2004;44(6):915-930. https://doi.org/10.1093/bjc/azh041

15. Jo HY, Bae JH. The relationship between North Korean refugee families' psychological environment of parenting and young children's prosocial behaviors. Journal of Korea Open Association for Early Childhood Education. 2014;19(2):91-114.

16. Na JY. Family disorganization in the North Korean refugee adolescent's oral life story and trauma. Journal of the Humanities for Unification. 2014;60:97-133.

17. Yoo JA. Characteristics of children of North Korean defectors: Focusing on elementary school students born in South Korea [master's thesis]. Seoul: Sogang University; 2015. p. 1-82.

18. Schlabach $S$. The importance of family, race, and gender for multiracial adolescent well-being. Family Relations. 2013;62(1):154-174. https://doi.org/10.1111/j.1741-3729.2012.00758.x

19. Gibaud-Wallston J, Wandersman LP. Development and utility of the parenting sense of competence scale. Touliatos J, Perlmutter BF, Strauss MA, Holden GW, Editors. Handbook of family measurement techniques .Vol. 3, Instruments and index. Toronto: Sage; 2001. p. 315.

20. Kim HC. Parenting stress and coping strategy test. Seoul: Proid; 2015.

21. Sandhu DS, Asrabadi BR. Development of an acculturative stress scale for international students: Preliminary findings. Psychological Reports. 1994;75:435-448. https://doi.org/10.2466/pr0.1994.75.1.435

22. Lee SJ. Relations between the acculturative stress and belief sys- 
tem, social support of international student. Journal of Yonsei Education Research. 1996;9(1):157-176.

23. Kim HC. Parenting attitude and type test. Seoul: Proid; 2013.

24. Park J. Classification of parent-child relationship types of children and early adolescents. Journal of Open Parent Education. 2020;12 (1):1-19. https://doi.org/10.36431/JPE.12.1.1

25. Lee RH, Chang HL. The influence of maternal acculturative stress on the child's achievement motivation among multicultural families: Focusing on the dual mediating effect of parenting efficacy and ego resilience. Journal of the Korean Society of Child Welfare. 2019;66:65-95. https://doi.org/10.24300/jkscw.2019.06.66.65

26. Kim MJ, Lee KN. Effects of infants' and toddlers' temperament and mothers' parenting self-efficacy on parenting behavior. Korean Journal of Childcare and Education. 2011;7(4):253-271.

27. Kim NH, Baek IK. The effect of child-rearing self-efficacy and pa- renting stress of married immigrant women on their children's preschool adjustment and social and peer competence. Early Childhood Education Research and Review. 2015;19(1):365-384.

28. Lovejoy MC, Graczyk PA, O'Hare E, Neuman G. Maternal depression and parenting behavior: A meta-analytic review. Clinical Psychology Review. 2000;20(5):561-592.

https://doi.org/10.1016/S0272-7358(98)00100-7

29. Yeon EM, Choi HS. The effect of parent's sex-role attitude on parent-child relationship in multicultural Families. Journal of the Korea Academia-Industrial cooperation Society. 2017;18(6):171-179. https://doi.org/10.5762/KAIS.2017.18.6.171

30. Lee SL, Peng MSC. The effects of group art therapy on mothers of children with special educational needs. Journal of the American Art Therapy Association. 2017;34(1):12-19. https://doi.org/10.1080/07421656.2016.1273697 